\title{
Participation Solicitation Design for Learner Engagement with Epistemic Objects and Situated, Collective Learning in Online Discussion Boards
}

\author{
Susan Gasson \\ Drexel University \\ sgasson@drexel.edu
}

\author{
James Waters \\ Neumann University \\ watersj@neumann.edu
}

\begin{abstract}
This paper describes research examining how we may design effective affordances for contextually- and socially-situated learning in professional domain courses mediated via digital technology platforms. Online learning affordances do not simply offer technology-related mechanisms for student interaction, but also provide mechanisms that allow situated professional practice and contextual domain knowledge to be incorporated into a digitized version of experiential learning. We distinguish between online learning affordances as technology mechanisms that guide normative actions and affordances as participation solicitations that provide learners with targeted affordances for active engagement in sociallysituated learning. Our analysis focuses on the domainspecific pattern sensitization that results from the joint creation of, and collective interactions with epistemic discussion objects and that leads to increased selfefficacy in active, experiential learning. The contribution is to demonstrate how solicitationaffordances complement technology affordances to support student engagement in interactive online learning, through examples of behavior and a framework for affordance configuration.
\end{abstract}

\section{Introduction}

The trend towards digitalization in business and education has exacerbated the separation of learning environments from situated practice identified by Donald Schön. In his argument that Universities have effectively separated articulated knowledge from context-specific learning, Schön built on the work of generations of educational theorists, but also made an argument for a virtual practicum, that represents the context of professional action, but also provides a safe space for learners to explore and perform skillful work within a domain of practice. Within this environment, learners engage in reflection-in-action, coached by an instructor who helps them to make sense of, and participate in, skillful practice [12]. In our work in this field, we have come to realize that coaching can include the preparation for contextualized learning, i.e. the design of learning materials and scaffolds for collective experimentation, both in practice and understanding. The joint creation and exploration of epistemic objects, whether these take the form of a shared product or contributions to online discussions that build into a contextualized epistemology of situated practice, is central to effective learning in domains of professional practice.

\section{Participation solicitations as affordances for active, experiential learning}

Asynchronous discussion boards have been a staple of online learning for at least 20 years. They have a low learning-curve, the timing and degree of participation is flexible (which allows for part-time study), and they afford an ability to build social relationships with other learners. But we know little about how to design discussion mechanisms to support active learning [10]. Social cognitive theory conceptualizes individuals as active agents who exert intentional influence over their functioning and learning in accord with their self-efficacy beliefs, defined as the extent to which people think their actions will result in success [1]. We need to explore how course scaffolding - the direction provided by technology participation mechanisms and participation frameworks configured by the instructor - enables learners to engage with the course community members, resources, and participation frameworks to encourage student self-efficacy and communal learning.

Affordances represent a resource or mechanism that the environment offers an individual, who must possess the capabilities to perceive and use it [6]. For example, an audio podcast may afford rapid learning for many online students, but does not afford learning for hearing-impaired individuals. Dreyfus and Kelly describe responsiveness to affordances as "experience in which the world solicits a certain kind of activity" [3, p. 52]. In designing online learning configurations, we distinguish between technology affordances, which comprise the generalizable mechanisms for action afforded by a digital learning environment platform (e.g. Blackboard) and participation solicitations, which afford instructor-configured mechanisms for student engagement in active learning experiences. Participation solicitations are recognized - and can therefore be taken advantage of - by students because 
of context-sensitive exposure to similar patterns of configuration or behavior in prior experience (a.k.a. pattern sensitization) [7]. New patterns of learning behavior can be reinforced via incentive systems (reward structures and grading rubrics), accompanied by rapid, formative feedback [5].

This is especially important for professional education. Schön argues that instructors should situate experiential learning within a "virtual practicum" that represents the world of practice, but provides a safe space in which students can practice skills and explore domain knowledge under the guidance of an instructor in the role of a coach or learning facilitator [12]. Experiential learning is central to the adaptive problem-solving and sensemaking that a virtual practicum involves [9]. Learners in courses involving traditional, instructor-led pedagogy treat the subject matter as disconnected pieces of information, whereas those who engage with constructivist, experiential, and collective learning view the subject matter as possessing a deep structure that emerges over time [11, 12]. New ideas and concepts are related to previous knowledge/experience - and therefore retained [9, 11].

Abstractions of this deep structure are treated as epistemic objects, which provide an organizing framework for ideas but "lack ... completeness of being" and possess "the capacity to unfold indefinitely” [8, p. 181]. This allows them to adapt, as learners gain understanding of a problem-situation. By providing an initial "straw man" framework for discussion and affording access to opportunities for learners to explore ideas with peers and tutors who can lead them through the zone of proximal development [13], instructors bridge the gap between what the learner can do without help and what he or she can achieve with guidance from a knowledgeable, skilled coach - who may be a peer learner [14]. Within the virtual practicum, students may direct their own learning and that of their peers by exploiting opportunities for individual experiential learning, peerlearning through interactive discourse, and joint learning through shared explorations of practice [12].

In the study that follows, we pursue the concept of designing relevant participation solicitations (targeted affordances for active engagement in social learning), that result in domain- or context-specific pattern sensitization to what constitutes skillful practice in such situations, and that enables students to engage with discussions as epistemic objects that produce situated, community learning.

\section{Research method}

This study analyzes student engagement with learning as part of twelve, ten-week, professional graduate (MS) courses in Library and Information
Science and Information Systems. Our sample courses, listed in Table 1, were selected to keep student capabilities comparable across courses. Our initial analysis focused on six Information Systems graduate courses, covering sections of Systems Analysis \& Design, IS Requirements Analysis, and Project Management courses across instructors and sections. We expanded our sample to include Library and Information Science courses to compare instructor and student approaches to peer learning across professional domains. This sample allowed us to explore a wide range of strategies in scaffolding practicum design across instructor- and domain-driven variations: organizing contextual knowledge sharing, affordances for peer and experiential learning, mechanisms for asynchronous student interaction, and support for metacognitive processes and self-efficacy in learning.

\section{Table 1. Course Sample and Domains}

\begin{tabular}{lll} 
Course & Section-size (ID) & Professional Domain \\
\hline IS-1 & $23(1 a), 24(1 b)$ & Intro Info System Analysis \\
IS-2 & 22 & Requirements Analysis \\
IS-3 & $22(3 a), 22(3 b)$ & Project Management \\
LIS-1 & $25(1 a), 19(1 b)$ & Intro to Bibliography \\
LIS-2 & $25(2 a), 24(2 b)$, & \\
& $25(2 c)$ & Info Resources \& Services \\
LIS-3 & $23(3 a), 25(3 b)$ & Social Context of Info. Professions
\end{tabular}

This paper combines findings from a number of short studies, using a mixed methods approach to data collection and analysis, combining qualitative content analysis with a quantitative analysis of online trace data from the Blackboard activity logs, to explore various indicators of successful learner engagement and to understand how students valued relevance. A major problem faced by online course designers is the question of determining what success looks like, for an online discussion. For each research question below, we combined attributes of observed behaviors or discussion content to develop a set of codes that were relevant to the research question at hand, rather than using simplistic measures such as number of posts (which do not reflect post quality or contribution).

The two coders analyzed sections of the data separately, then compared notes to arrive at a set of shared categories for each research question that captured the complexity of learner engagement, were of relevance to experiential learning, and explored how contextual knowledge for professional practice was acquired and shared between peer-learners. As we worked, we kept memos relating to how we conceptualized complex constructs, gray areas, and new ideas, as well as process issues such as "how do I code this?”. We constantly discussed these memos 
throughout our analysis, developing more sophisticated concepts as we worked on successive samples and often returning to recode prior data sets.

Our overriding research question was to explore what elements affected the perceived relevance of affordances, so that these were seen as solicitations for engagement in situated learning.

This led to a number of detailed research questions, each of which is explored in a separate section of the findings, below. We suggest ways of scaffolding professional courses to incentivize peer knowledge exchange that situates community learning in the context of practice. We present examples and findings from our analysis to indicate how a professional course instructor might design a virtual practicum for situated learning that addresses both the knowledge and the transferable skills required for practice in Information Science and Systems professional domains.

\section{Designing discussion affordances for student engagement}

\subsection{Maximizing intrinsic motivation}

Our first detailed research question was what is the role of intrinsic motivation in student engagement with learning?

While there is no agreed-upon definition of learner engagement in the psychology or education literatures, we initially adopted the concept of intrinsic motivation to indicate engagement with a task and its outcomes, so that engagement is defined as psychological commitment to the process, compared to (often token) participation. While there are several instruments to evaluate the degree of intrinsic motivation, it is difficult to administer such surveys in an online learning environment, as the survey naturally disrupts student engagement, or fails to capture real-life motivators when administered post hoc. We therefore decided to evaluate student engagement through trace data signs: employing a combination of message length, thread-depth and thread diversity in peerknowledge-construction discussions. We analyzed a range of courses and discovered that specific indicators allowed us to visualize how engaged students were by understanding what was normal for a course where students were relatively disengaged from the domain of practice, to one where they were highly engaged with the proxy form of experiential learning represented by debate between practitioners with at least some relevant context-specific expertise.

Table 2 compares two sections of the same course, one with a heavily moderated discussion and one with a relatively unmoderated discussion (the instructor only participated when student discussions were factually incorrect or when students were patently not engaging with the discussion). Our content analysis categorized posts by their use of vocabulary that indicated strong or weak engagement with other students, interest and enthusiasm for the topic.

Table 2. Indicators of student engagement

\begin{tabular}{|l|c|c|}
\hline & $\begin{array}{l}\text { IS-1 (a - Low } \\
\text { engagement) }\end{array}$ & $\begin{array}{c}\text { IS-1 (b - High } \\
\text { engagement) }\end{array}$ \\
\hline $\begin{array}{l}\text { Message length } \\
\text { (Agile Question) }\end{array}$ & 110.29 & 218.59 \\
\hline Msg. length (Goals) & 115.35 & 208.36 \\
\hline $\begin{array}{l}\text { Msg. length (Analyst as } \\
\text { problem solver) }\end{array}$ & 100.38 & 212.35 \\
\hline $\begin{array}{l}\text { Thread } \\
\text { (Agile Question) }\end{array}$ & 80 & 97 \\
\hline Thread length (Goals) & 106 & 97 \\
\hline $\begin{array}{l}\text { Thread length (Analyst } \\
\text { as problem solver) }\end{array}$ & 52 & 74 \\
\hline Subthreads (Agile) & 12 & 21 \\
\hline Subthreads (Goals & 19 & 22 \\
\hline $\begin{array}{l}\text { Subthreads (Analyst as } \\
\text { problem Solver) }\end{array}$ & 25 & 15 \\
\hline Participants(Agile) & 20 & 25 \\
\hline Participants (Goals & 21 & 25 \\
\hline $\begin{array}{l}\text { Participants (Analyst as } \\
\text { problem solver) }\end{array}$ & 19 & 25 \\
\hline
\end{tabular}

Students who were more engaged with the topic posted longer responses to the initial question, that contained stories and analogies to relate their response to the structure of the question. They returned frequently, many of them participating daily - a really unusual phenomenon with this type of asynchronous learning course. Rather than the rather pedantic and poorly-informed perspectives that students in an introductory course tend to post - and that were typical of section IS-1(a), students in the IS-1(b) section did not appear to view this as an individual posting assignment, but debated ideas with other students, often reaching agreement among a subgroup (in a subthread), then presenting this for others to consider, The debate spilled over into the following week.

So what was the difference? The instructor for section IS-1(a) was someone who we will call "Professor Entertaining." He always received very high student evaluations and was considered a skillful instructor by the students, as he related anecdotes and funny stories, discussed the latest sports results, and generally took an interest in his students' lives. The instructor for section IS-1(b) was someone who we will call "Professor Serious." $\mathrm{He}$ was also an experienced IS Professional, but preferred to recount 
anecdotes in the audio lectures that he prepared to accompany course materials online. His moderation style was relatively hands-off: he intervened only when students had posted misleading or off-topic analyses of a situation - and then only gently, to nudge students into a second round of debate. This left students with the impression that they were learning less from his courses, than they did with Professor Entertaining.

\subsection{Instructor moderation of discussions}

Our second detailed research question was what role does instructor participation play in student engagement with peer-learning?

We found that instructors varied widely when it came to how much they moderated discussions. Some were practically invisible while others could best be considered intrusive. We were able to compare multiple different sections of the same courses, but taught by different instructors.

The graph in Figure 1, taken together with Table 3, summarizes our analysis of the impact of instructor moderation on student engagement. This seems to indicate an inverse relationship between discussion board moderation and student engagement with the topic. Between sections of the same course the more that instructors posted, the less students responded. The most startling example being the difference between IS- $1 \mathrm{a}$ and IS-1b, the instructor for IS-1b was almost invisible yet each post generated double the amount of student activity as the same topic generated in section IS-1a. Although this finding appears on face value to be counter-intuitive, a content analysis revealed the reasons for this impact. This was due to student expectations - when an instructor interacted frequently and often sociably in discussions, the focus of the discussion was less domain oriented and more sociable. Students enjoyed these discussions and their perception was that they had learned a lot on these courses. But a comparative content analysis of the domain knowledge explored showed a much more superficial understanding across the course. A social network analysis confirmed our suspicion - most posts in section IS-1a were directed at the Instructor, whereas most posts were directed to other students in section IS-1b. Interactive posts generated responses and follow-up debate, that led to deeper and more diverse constructs being generated across the community of learners.

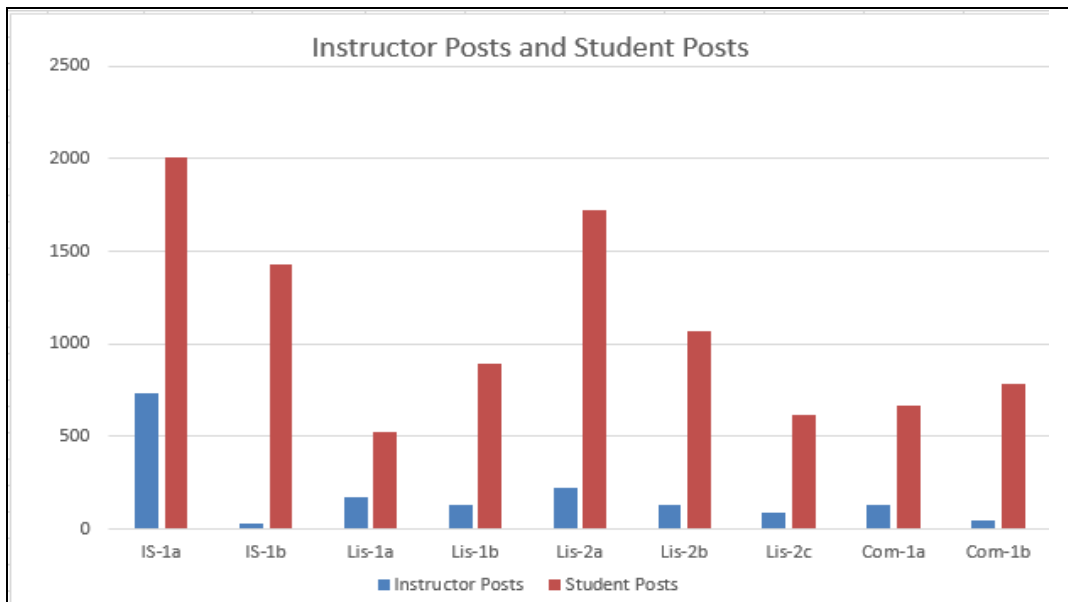

Figure 1. Relationship between Instructor moderation and student engagement with topic

Table 3. Impact of Instructor Moderation on Student Engagement With Topic

\begin{tabular}{|l|c|c|c|}
\hline Course & $\begin{array}{c}\text { Instruct } \\
\text { or Posts }\end{array}$ & $\begin{array}{c}\text { Student } \\
\text { Posts }\end{array}$ & $\begin{array}{c}\text { Ratio } \\
\text { S/I }\end{array}$ \\
\hline IS-1a & 735 & 2010 & 2.73 \\
\hline IS-1b & 32 & 1426 & 44.56 \\
\hline LIS-1a & 172 & 520 & 3.02 \\
\hline LIS-1b & 132 & 897 & 6.80 \\
\hline LIS 2a & 225 & 1721 & 7.65 \\
\hline LIS-2b & 130 & 1071 & 8.24 \\
\hline LIS-2c & 91 & 618 & 6.79 \\
\hline COM-1a & 134 & 670 & 5.00 \\
\hline COM1b & 46 & 788 & 17.13 \\
\hline
\end{tabular}

What happened in course LIS-2c?

It can be seen from Table 3 that course LIS-2c was an outlier, with relatively low levels of instructor moderation, but also low levels of student engagement. (Although the Student-Instructor post ratio was similar to that on other courses, instructor participation was much lower than those with a similar ratio).

When interviewed, the Instructor noted that there were very few highly active students. They stated that much of the communication with students took place outside the discussion board via personal emails.
Students in fact were allowed to opt out of discussions altogether, signalling that discussions were considered to play a small part in student learning. Several students did opt out.

The Instructor also noted that several of the students either failed due to non-participation or had very low levels of participation. Several questions did not appear designed to generate discussion, for example there were three separate questions that just asked students to describe their experience of a site visit or their experience with an online reference 
source, rather than producing an analysis of their findings:

- Describe your experience visiting the reference desk of your local library

- Describe your experience using the IPL system or another virtual library

- Create 4 questions for practice with the IPL system One question required students to critique the course text, an almost impossible task for those with no domain knowledge.

\subsection{What makes a question relevant?}

Our third research question was what makes a question sufficiently relevant to learners that they engage with the discussion?

To support the sensitization to patterns of behavior and collective co-construction of knowledge that underpin socially-situated experiential learning, we need to provide students with the intellectual tools to engage in effective peer debate. Our own learning framework was developed over a series of iterative studies [5]. It provides instructions for participation and a rubric for evaluation that emphasizes a form of participation where the learner:

- Consistently participates, debates points, and provides unique insights which significantly advance the understanding of others.

- Provides resources and interpretations of topic from research and reading.

- Frequently interacts with other students in debate, adding to, complicating, and extending their insights multiple times [5].

Rapid, formative feedback in the first week emphasizes the use of stories, analogies, and examples to illustrate the reasoning behind points that the student makes in their posts. Contextualization is actively rewarded, as is the use of "war stories" from the front line of application domain practice. The consequent debate reflects a situated, polycontextual view of professional practice.

\section{Question design}

Some general findings emerged from our analysis of question design and the contingencies that led to student engagement with a question or topic. Timing was important. The most engaged-with questions tended to be those which were posted first. Questions posted later tended to have less student uptake. After highly engaging initial questions, with frequent deep threads, later questions tended to show student fatigue. Other findings related to question design - these are illustrated with three examples from a Systems Analysis course.
Question 1. Cooking Up a new project. I want you to cook up a systems development project (real or imagined). Describe the goal(s), the objective(s) of the project and the scope of the work the systems analyst for the project. Post your goals, objectives and scope by around Thursday of this week. I'd then like each of you to comment a bit on each other's work.

This question was particularly effective in generating engagement, with 150 posts in total (the second longest thread). There were several sub-threads that were extremely deep (7 or 8 levels) and most messages were posted student to student. This question encouraged collaboration and allowed students to negotiate the meaning of the question. An international student misunderstood the meaning of goals and objectives, but other students tactfully corrected his misapprehensions, so the misunderstanding was constructive for learning.

Question 2. Fact finding. I would like each of you to initially focus on one fact finding technique, your contribution should be a critical (but brief) examination of that technique within the domain of systems analysis.

This post was regarded as moderate quality with fair thread depth and length. It was a reasonably openended problem but inspired less cooperative interstudent activity; students mostly discussed different techniques.

Question 3. Fast or Slow? Critically evaluate the author's FAST approach. Is it useful? Practical? What are some alternatives? Is this a "real" model that could be used on "real" projects?

This question elicited very little student interaction with a total of 46 posts and a limited sub-thread depth: mostly a question then a single response. Most responses appeared targeted directly at the course Instructor. This may be due to the fact that the question incorporated five questions in one: one open-ended question, and four bounded questions that covered different ground. Resolving these conflicts in scope was not pitched as a cooperative activity. So students did not attempt to cooperate, but gave up on the discussion.

Dimensions of topic relevance. As we explored the relevance issues, we identified three dimensions that appeared to determine whether students would become engaged in exploration of a topic or question.

Students became highly engaged when:

- The question topic related explicitly to the course learning objectives ("at the end of this course you will be able to ...”);

- The question domain related to their professional interests (i.e. answering it would help in job advancement or recruitment activities); 
- The question identified clear experiential learning outcomes that allowed students to practice professional skills, to develop contextually-situated expertise, or to acquire domain-relevant knowledge.

A good example is provided by the thread extract from the Requirements Engineering course, shown in Table 4. It explores a key requirements engineering domainrelated issue, about the value and problems of prototyping. Prototyping is a valuable requirements gathering tool, but its value is constrained by the emotional attachment that software engineers develop for code that they have spent time creating and refining.

Because developers create prototypes before they appreciate the system requirements as a whole, prototypes introduce unintended design constraints. "Letting go" was a term suggested by a student in an earlier week's discussion. It requires that they abandon or replace the prototype design once it has served its purpose for exploring requirements. This is difficult, as designers become emotionally attached to their prototype design as they construct and explore epistemic representations of alternative designs [8].

\section{Table 4 Exploratory discussion of the value of 'letting go' in prototyping}

\begin{tabular}{|c|c|}
\hline $\mathrm{S} 1$ & $\begin{array}{l}\text { tting go of a project you've worked on is difficult. Everyone has some attachment to what they've already done and it is } \\
\text { fficult to just discard it. However, there is a learning curve, where you learn by doing. If you were to do it over, you } \\
\text { ght do it differently but does that necessarily mean starting over? Sometimes yes, but more often it will wait until the } \\
\text { xt time the system needs to be upgraded In terms of prototyping, I think it is still difficult to completely start over. Both } \\
\text { e developer and the customer will be used to seeing one interface and this will tend to be used for future iterations. Once } \\
\text { e customer sees one product, unless it is unsatisfactory, that becomes the standard for comparison. To avoid this, maybe } \\
\text { s best to start with a few different prototypes to see which ones work better. There may be a consensus favorite, but the } \\
\text { al product would most likely incorporate something from the existing alternatives to meet all requirements. }\end{array}$ \\
\hline $\mathrm{S} 2$ & $\begin{array}{l}\text { situation like this I would say "YES, definitely I would like } \\
\text { atch!” But there's the whole timing thing. There's never enou } \\
\text { rks because there's always something broken. The only thing } \\
\text { eady there }\end{array}$ \\
\hline S3 & $\begin{array}{l}\text { I am sure switching to something you had put a great deal of time and effort into would become } d \\
\text { in the article, Eric Raymond found two variations of code that both worked well for him but on } \\
\text { functionality. Eric then chooses the popclient code by Carl Harris making the switch. While I d } \\
\text { threw away his code within fetchpop, he added to the fetchpop code making it better in a later rel } \\
\text { that as a waste of time. Eric learned from the mistakes of the popclient author and might have imp }\end{array}$ \\
\hline S4 & $\begin{array}{l}\text { I don't think that "Starting over" is a problem though with most groups. I disagree with the terminology, th } \\
\text { my concept of "starting over" is different than what is implied. When I think starting over, I think } \\
\text { everything an back to the drawing board, square 1, etc.... But I don't think that adjustments made durit } \\
\text { phases are starting over: the problem is still the same, the requirements are still the same, the personnel } \\
\text { likely) not change, and all the work done in the assessment phases is still there (albeit with maybe a few } \\
\text { high priority requirements). }\end{array}$ \\
\hline S5 & 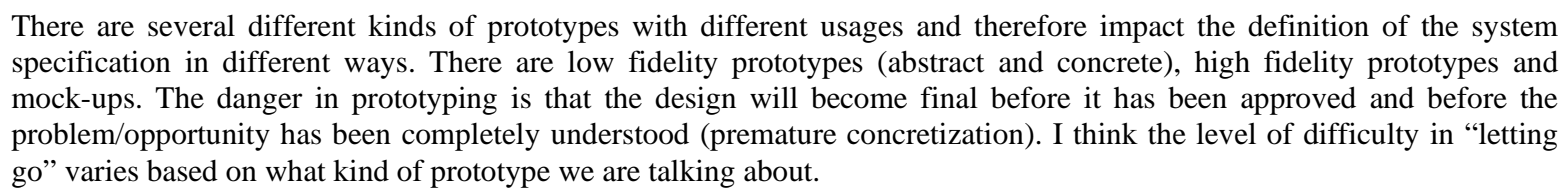 \\
\hline
\end{tabular}

Most students recognized the dilemma. They presented examples from their personal experience and then engaged at a deep level in discussing the meaning of other students' experiences.

The question format drew students into a deep discussion of exactly what is meant by "letting go" and a deeper examination of the nature of prototypes. This discussion contained the single most engaging thread of the entire course - students were still discussing it in the following week. It was related to course material, students' first-hand professional experience, and presented experiential knowledge that would allow students to advance their careers or impress recruiters.

\subsection{Role of student topic reframing as participation solicitations in peer learning}

Our fourth research question was What role does student reframing of the discussion topic play in peerlearning? What form of solicitation affordance can encourage this reframing behavior? A phenomenon that was widespread, in courses where instructor 
moderation of peer knowledge construction was minimalist, was the tendency for students to reframe questions that they viewed as less relevant, so that they presented opportunities for experiential knowledge acquisition.

The opportunistic hijacking of the discussion topic shown in Table 5 demonstrates how an early student response provides a new dimension that is tangential to the problem-structure intended by the instructor's question formulation, focusing the debate on the value of multi-domain experiential knowledge rather than key project management skills.
This provided a critical reflection-in-action moment, as students keyed into this reframing, to explore the value of multi-domain experience vs. abstract transferrable skills. It provided the longest thread in the whole course discussion (64 posts, with 18 participants), with an average message length of 630 words (twice the course average). The instructor commented that they were planning to incorporate this element into future discussions of the most valuable Project Manager experiential knowledge, as students were so engaged with it.

\section{Table 5. A student reframes the problem-structure for others in in peer debate}

\begin{tabular}{|c|c|}
\hline \multicolumn{2}{|r|}{ Question: What do you see as the key project management skills? (Extract from start of thread) } \\
\hline S3 & $\begin{array}{l}\text { Key project manager skills: Experience in domain affected by the project. Example, if a certain application needs to be } \\
\text { changed, a project manager who has completed multiple integrations in this domain is extremely valuable }\end{array}$ \\
\hline S11 & $\begin{array}{l}\text { I really liked one of the key bullet points you made about project manager skills around "shared engineering experience". } \\
\text { Everyone will understand this too to some degree if they have worked in a PM role or a role where you work with } \\
\text { developers closely. One of the underlying themes is really more of a psychological and human emotion that we all have. } \\
\text { People naturally don't like to be told what to do by others. However, this animosity is usually gone when the person given } \\
\text { the orders is respected. Respected for either their technical background or their ability to logically explain why something } \\
\text { needs to be done goes a long way }\end{array}$ \\
\hline S10 & $\begin{array}{l}\text { S11, Five years ago I would have wholeheartedly agreed with you that "experience in domain affected by the project" and } \\
\text { "shared engineering experience" would be key experiences for a project manager and I still do think they are highly } \\
\text { valuable for software/engineering project managers. However, in the past five years I have had multiple experiences with } \\
\text { project managers that do not have specific domain knowledge in my industry but have experience in software } \\
\text { development or software project management. They have been highly successful as project managers and delivered } \\
\text { projects on time and on budget. I wonder if project management skills are transferrable across industries. }\end{array}$ \\
\hline S3 & $\begin{array}{l}\text { Thanks s10. I think one of the biggest issues I've seen in my projects is that someone has unrealistic expectations of a } \\
\text { project based off of their past experience. Knowledge transfer of the team or leadership to properly identify risk and } \\
\text { historically challenges that may be less obvious, such as the political climate of a project. I know if I went to attempt to } \\
\text { run a spaceship project I'd have a huge ramp up to appreciate the intimacies of past failures! }\end{array}$ \\
\hline S8 & $\begin{array}{l}\text { We often had problems with managers that knew nothing about what we did. Often they would promise customers things } \\
\text { we just didn't have the ability to do. (Quite often, when I had to escalate to a manager, I would get direct messages from } \\
\text { the manager asking, "can we do that?") We had some managers that would just tell customers we could do things that } \\
\text { were impossible. But we also had managers that would ask us what we could do. I think the fundamental point I have here } \\
\text { is that a good project manager may not have directly applicable knowledge of the subject domain but knows enough to ask } \\
\text { for expertise when it is required. }\end{array}$ \\
\hline
\end{tabular}

\subsection{Mechanisms for contextual scaffolding}

Our fifth research question was how can we scaffold contextual knowledge, to allow students to understand new application domains?

Online discussion necessarily introduces students to new and advanced concepts. Students typically start with limited capabilities in new domains [13] and need support [2]. Careful use of scaffolding can extend student capability. Such scaffolding can include exemplars, task structuring, supporting material, refection and the support of more knowledgeable peers [2]. We discovered that the supporting materials could influence discussion quality - a selection of examples is given below.
Example 1. Info. Services course ethics question You've been asked to read the ALA Code of Ethics plus two other codes of ethics of your choice. What did you learn from this process?Did any common themes or concerns tend to emerge? What did you relate to in the ALA Code of Ethics?Were there things that seemed problematic, or that you disagreed with? Students were provided with:

- A long list of codes of ethics URLs

- Three abstract ethics articles

- A body of solid material but which did not directly relate to the posted question or give a framework for answering the question

This question generated a mere 12 replies with almost all being direct responses to the Instructor. Clearly students did not feel well enough prepared to enter into peer learning interactions. Student posts 
basically concluded 3 things: that codes of ethics were important, that they should be explicit, and that they should be capable of evolving over time, but they all seemed to reach identical, high level conclusions indicating little individual understanding.

Example 2. Second ethics question The following question from the same course elicited three times as many responses and multiple deep threads:

Can ethical behavior really be codified by a professional organization? Can ethical behavior be enforced? How?

For this question the supporting material included

- A description of ethical models

- A worksheet for ethical decision making outlining - Actions and consequences

- Responsibilities and obligations - a theoretical and pragmatic framework for debate

- Three sparse pages of bullet-points mapping out the contextual domain of practice.

These resources provide students with a clear context for the discussion-task and a set of relevant tools to achieve it without large amounts of reading. Students were almost equally split about whether an organization could enforce ethical behavior effectively, although most thought that organizations should be able to define ethical behavior.

\section{Example 3. Database model creation}

When questions involve expertise in professional practice, more knowledgeable students would often act as peer "instructors" leading students in the zone of proximal development [13]. This trend was especially true for the more technical courses we analyzed. This example taken from a systems Analysis course thread on Entity Relationship Diagrams shows the most influential participant (measured by no. of threads started, length and depth of threads started, and branching of threads) tactfully correcting student misapprehensions about both modelling techniques and formalisms - his comments included:

The system analyst assists in gathering the requirements for the database. They also model the data and processes for the database system.

For 2NF the Sale entity should be looked at because it has a concatenated key. There are no attributes here, so this in 2NF. For 3NF there are no nonkey attributes dependent on other nonkey attributes. So this model is in $3 N F$.

Should the Title entity have a a Primary Key? Since Title is an entity should it also be a table when implementing the database?

Why are the primary keys (SupplierName, CategoryName) in the Supplier entity and the ProductCategory entity also foreign keys?
Students engaged deeply with the question given in example 3, despite difficulties in understanding the technique, as it provided knowledge relevant to their future careers (the structure of an Entity relationship Diagram for a Library System). Assistance from peer learners was especially valued. Students were happy to assist each other, as much for the intrinsic satisfaction of explaining practice in areas where the course materials had failed to do so, than for any explicit recognition or reward.

\subsection{Challenges to instructors' framing of knowledge relevance across domains}

Our last research question was how should instructors interpret challenges to their framing of knowledge relevance across domains?

As instructors pose questions and assignments for which students construct a collective view of the domain of practice, they present a picture of the relevance of specific activities across domains. Almost universally these presentations of relevance are accepted by students. It is therefore important to design participation solicitations that emphasize the contextual and experiential knowledge that the instructor would want students to take away from the course, rather than leaving these to chance (as in the outlier course LIS-2c discussed above). As organizations become more complex, polycontextual understanding becomes more central to successful student engagement with educational outcomes. It is not only students who must be lifelong learners, but also instructors who teach across domains.

Occasionally students will challenge the instructor's framework for cross-domain relevance. An interesting example occurred in course LIS-2c. In one assignment students were asked to create a WIKI page. The instructor intimated that this was an almost trivial task and identical to creating a formal web page. This generated a heated response from a student who was a professional website designer:

Respectfully speaking, Wikis are used for content editing, and not web design. The professor is wrong when she said that designing a website is easy. One has to consider things like web standards, user compatibility, and ADA compliance. It is not about putting a bunch of clipart on a page with some links.

Real web design is not easy, and learning to use a Wiki will not make you a web designer. ... Using a Wiki is NOT web design. The professor should have said "use this to design a simple page with links because that is all we have time for."

In presenting professional domain courses to digital natives, we must encourage such challenges, viewing these as opportunities to incorporate multi-domain knowledge into our course designs. 
Table 6. Technology affordances vs. solicitation affordances in online learning environments

\begin{tabular}{|c|c|c|c|}
\hline \multicolumn{2}{|c|}{$\begin{array}{l}\text { 6a. Technology Affordances of Asynchronous } \\
\text { Use of Blackboard Content \& Discussion Board }\end{array}$} & \multicolumn{2}{|c|}{$\begin{array}{l}\text { 6b. Participation Solicitation Affordances of } \\
\text { Community-Based, Situated \& Experiential Learning }\end{array}$} \\
\hline Segmentation & $\begin{array}{l}\text { Allows instructor to generate new } \\
\text { discussion boards for unique topics }\end{array}$ & Relevance & $\begin{array}{l}\text { Allows reader to identify contextual } \\
\text { relevance of a specific post or topic }\end{array}$ \\
\hline Posting & $\begin{array}{l}\text { Allows individual to post } \\
\text { formatted written perspective on } \\
\text { question/topic }\end{array}$ & Contextualization & $\begin{array}{l}\text { Presentation of context-related signs and } \\
\text { indicators that allow a learner to place } \\
\text { an idea or discussion post in context of } \\
\text { domain-related practice }\end{array}$ \\
\hline Ownership & $\begin{array}{l}\text { Allows reader to identify post } \\
\text { originator }\end{array}$ & $\begin{array}{l}\text { Context } \\
\text { sensitivity }\end{array}$ & $\begin{array}{l}\text { Allows learner to become sensitized to } \\
\text { patterns of behavior or contextual } \\
\text { factors that indicate domain relevance }\end{array}$ \\
\hline $\begin{array}{l}\text { New thread } \\
\text { generation }\end{array}$ & $\begin{array}{l}\text { Allows instructor or students to } \\
\text { start a new thread when topic } \\
\text { warrants it }\end{array}$ & $\begin{array}{l}\text { Experiential } \\
\text { knowledge } \\
\text { acquisition }\end{array}$ & $\begin{array}{l}\text { Learning by doing (interactive analysis); } \\
\text { Learning by debating (proxy experience } \\
\text { via stories, analogies, exemplars) }\end{array}$ \\
\hline Time stamping & $\begin{array}{l}\text { Allows reader to relate posts to } \\
\text { specific prior posts or points in the } \\
\text { sequence of debate }\end{array}$ & Engagement & $\begin{array}{l}\text { Enables learner to relate their own } \\
\text { interests and experience to that of others, } \\
\text { to acquire proxy experiential knowledge } \\
\text { through online debate }\end{array}$ \\
\hline $\begin{array}{l}\text { Linking/ } \\
\text { attachments }\end{array}$ & $\begin{array}{l}\text { Allows poster to link to (reference) } \\
\text { external resources or attach } \\
\text { analytical representations, etc. }\end{array}$ & Peer Learning & $\begin{array}{l}\text { Enables learner to engage in proxy } \\
\text { experiential learning by comparing their } \\
\text { first-hand domain experience with that } \\
\text { of peer learners from other domains }\end{array}$ \\
\hline \multirow[t]{2}{*}{ Collaboration } & $\begin{array}{l}\text { Enables the user to engage in } \\
\text { interactive debate via threading } \\
\text { and time-stamped posts }\end{array}$ & Enculturation & $\begin{array}{l}\text { Immersion in socio-cultural aspects of } \\
\text { situated practice, to understand } \\
\text { experiential knowledge in context }\end{array}$ \\
\hline & & $\begin{array}{l}\text { Polycontextual } \\
\text { learning }\end{array}$ & $\begin{array}{l}\text { Relates frameworks for practice to allow } \\
\text { learner to translate knowledge \& } \\
\text { practice across application domains. }\end{array}$ \\
\hline
\end{tabular}

\section{Technology platform affordances vs. participation solicitations in social learning}

In Table 6, we synthesize our findings on the generalized, technology affordances for discussion provided by the Blackboard learning platform vs. a the participation solicitation affordances that we encountered in our study. Participation solicitation affordances are presented as a high-level conceptualization of the mechanisms by which students acquired experiential knowledge, became sensitized to domain-specific contextual factors, and became enculturated in the competencies and situated behaviors presented as best practice in interactive debate with practitioners-in-context. This knowledge provides the basis for the virtual practicum recommended by Donald Schön [12].

We placed the paper in context by discussing the need for contextualized, situated learning, which presents course knowledge in the context of relevant application domain situations, and which allows students to acquire experiential knowledge through proxy mechanisms such as learning by doing in course projects and through debate with peer learners about the nature and processes of expert practice that are related to the contingencies of context and of situation. In a series of studies that explore the nature of peer learning and socially-situated sensemaking, we have been increasingly persuaded of the value of stepping back, as an instructor, to provide opportunities for learning from knowledgeable peers in the community of learners. Our analysis of the effect of instructor moderation on student engagement with debate highlighted the unexpected ways in which we constrain peer learning through what we perceive as good instructional practice. A second element that arose from the analysis is the way in which online debate presents an epistemic 
object, providing an external representation of ideas that allows these to be explored collectively [8].

The understandings generated through discussion play multiple roles: (i) they mediate knowledgesharing between domains, (ii) they provide a framework for knowledge translation across the participation frameworks of various work-contexts [4], and (iii) they build into a communal structure-ofinterpretation around which aspects of the situation can be debated [11]. The ability to relate situated knowledge to multiple participation frameworks allows students to relate this abstraction to their own experience [7].

\section{Conclusions}

We observed the centrality of context sensitivity in community knowledge-building - the sensitization to patterns in the practice environment through interactions with instructional resources and peer learners that allows us to develop joint, experiential frameworks for professional practice. We presented a series of analyses that provide evidence for the adaptive, epistemic nature of knowledge coconstruction in community learning, supplemented with a framework contrasting comparing generalizable technology affordances for access to discussions with the constructivist participation solicitation affordances required to use those discussions for the type of situated, interactive learning needed to become a knowledgeable practitioner in a professional domain.

The main contributions to knowledge are:

- A distinction between generalizable affordances provided by online technology platforms, and configured affordances for engagement with socially-situated learning, which we term participation solicitations;

- Examples of the various forms of configuration and course scaffolding/design that affect the ways in which participation solicitations fit with student learning needs;

- An exploration of community discussions as epistemic objects [8] and the shared domain coach roles of the instructor and peer-learners in supporting social-constructivist, experiential learning as part of a virtual practicum [12].

The intent is for the affordance framework, configuration learning points and examples, and the concept of discussion products as epistemic objects to form the basis of future course design. Future studies will explore how to define specific solicitation affordances to support common patterns for interaction that achieve polycontextual knowledge exchange [7]. By their nature, epistemic objects are open to interpretation and therefore provide a shared participation framework, that students co-construct and adapt in order to understand domain-related knowledge, problems, and skills [8]. Discussioncentered participation solicitations are the perfect vehicle for this type of concept exploration - when supported with an initial structure for ideas that is open enough to adapt, but defined enough to act as a "straw man" model of real-world practice.

\section{References}

[1] Bandura, A., Social Foundations of Thought and Action: A Social Cognitive Theory, Prentice Hall, Englewood Cliffs, NJ, 1986.

[2] Cho, M.H., \& Cho, Y., "Online instructors' use of scaffolding strategies to promote interactions: A scale development study.", The International Review of Research in Open and Distributed Learning, 17(6), 2016, 108-120.

[3] Dreyfus, H.L. and Kelly, S.D., "Heterophenomenology: Heavy-handed sleight-of-hand", Phenomenology and the Cognitive Sciences, 6(45-55), 2007,

[4] Engeström, Y., Engeström, R., and Karkkainen, M., "Polycontextuality and boundary crossing in expert cognition: Learning and problem solving in complex work activities", Learning \& Instruction, 5(4), 1995, 319-336.

[5] Gasson, S. and Waters, J., "Using A Grounded Theory Approach To Study Online Collaboration Behaviors", European J. of Information Systems, 22(1), 2013, 95-118.

[6] Gibson, J.J., The Ecological Approach to Visual Perception, Houghton Mifflin., Boston, MA, 1979.

[7] Goodyear, P., de Laat, M., and Lally, V., "Using pattern languages to mediate theory-praxis conversations in design for networked learning", ALT-J: Research in Learning Technology, 14(3), 2006, 211-223.

[8] Knorr Cetina, K.D., "Objectual Practice", in T.R. Schatzki, K.D. Knorr Cetina, and E. Von Savigny, (eds.): The Practice Turn In Contemporary Theory, Routledge, New York, 2001, 175-188.

[9] Kolb, D.A., Experiential learning: Experience as the source of learning and development, Prentice-Hall, Englewood Cliffs NJ., 1984.

[10] Richmond, A.S., Bacca, A.M., Becknell, J.S., and Coyle, R.P., "Teaching Metacognition Experientially: A Focus on Higher Versus Lower Level Learning", Teaching of Psychology, 44(4), 2017, 298-305.

[11] Scardamalia, M. and Bereiter, C., "Knowledge building: Theory, pedagogy, and technology", in K. Sawyer (Ed.) Cambridge Handbook of the Learning Sciences, Cambridge University Press, New York, 2006, 97-118.

[12] Schön, D.A., Educating the Reflective Practitioner, Jossey-Bass, San Francisco, CA., 1987.

[13] Vygotsky, L.S., Mind In Society, Harvard University Press, Cambridge, MA, Translated 1978.

[14] Waters, J., "The impact of Instructor Intervention Style on Student Activity in Asynchronous Online Learning Discussion Boards", E-Learn 2012, October 9 - 12, 2012. 